\title{
Comparison of Phytochemicals and Antioxidant Activities of Berries Cultivated in Korea: Identification of Phenolic Compounds in Aronia by HPLC/Q-TOF MS
}

\author{
Dae-Woon Kim, Hyun-Ah Han, Jong-Kuk Kim, Da-Ham Kim, and Myung-Kon Kim \\ Department of Food Science and Technology, Jeonbuk National University, Jeonbuk 54896, Korea
}

\begin{abstract}
Aronia, blueberry, Korean raspberry, blackberry, mulberry, and red raspberry fruits cultivated in Korea were evaluated for total phenol content (TPC), total flavonoid content (TFC), total anthocyanin, and ascorbic acid content. All berries were assayed for antioxidant activities determined as 2,2-diphenyl-1-picrylhydrazyl free radical scavenging activity, 2,2'-azino-bis(3-ethylbenzothiazoline)-6 sulphonic acid free radical scavenging activity, and ferric reducing antioxidant power. Individual phenolic compounds in aronia were also identified using high-performance liquid chromatography/ quadrupole-time of flight mass spectrometry. TPC, TFC, total anthocyanin, and ascorbic acid contents of the fruit samples ranged from 17.05 to $135.55 \mathrm{mg}$ of gallic acid equivalent/g dry weight (dw), 1.0 to $8.59 \mathrm{mg}$ of rutin equivalent/g dw, 2.55 to $24.43 \mathrm{mg}$ of cyanidin-3-O-glucoside equivalent/g dw, and 3.14 to $19.45 \mathrm{mg}$ of ascorbic acid equivalent/g dw, respectively. Aronia and Korean raspberry showed the highest TPC, TFC, and total anthocyanin while red raspberry had the highest ascorbic acid content. Antioxidant activities showed positive correlations to phenolic and anthocyanin contents suggesting antioxidant activity of berry samples is due to these compounds. Aronia had the highest antioxidant value among fruits.
\end{abstract}

Keywords: anthocyanins, aronia, berry, HPLC/Q-TOF MS, phenolic compounds

\section{INTRODUCTION}

The nutritional and functional properties of fruits and vegetables are attributed by their dietary fiber and micronutrients such as minerals, vitamins, and carotenoids. Several studies have also confirmed that fruits contain a variety of bioactive components commonly known as phytochemicals with potential beneficial effects on human health. The most prevalent and extensively investigated phytochemicals in fruits consist of a wide range of phenolic compounds which are associated with different biological activities including antioxidant activities (Türkben et al., 2010; Murphy et al., 2012). The term phenolic compound refers to plant secondary metabolites with a number of different chemical structures containing benzene rings with one or more hydroxyl substituents (Randhir et al., 2004). These compounds range from simple molecules to highly polymerized and complex ones, which contain a huge variety of phenolic acids, flavonoids, and colored anthocyanins (Velderrain-Rodríguez et al.,
2014). These compounds have been proven to have nutraceutical attributes including anti-aging and anti-inflammatory effects as well as reduction of cardiovascular, metabolic, neurodegenerative diseases, and cancer (Liu et al., 2014; Grosso et al., 2017).

Berries are colorful fruits prevalently consumed in the human diet as fresh and processed forms such as juices, yogurts, jellies, jams, and dried products. They have been reported to be rich in a variety of phenolic compounds such as anthocyanins, flavonols, catechins, benzoic acid, and cinnamic acid (Kalt et al., 2001; Giovanelli and Buratti, 2009; Sariburun et al., 2010). Hence, extracts of berry fruits such as blackberry, black raspberry, blueberry, cranberry, red raspberry, and strawberry were previously found to inhibit growth and stimulate apoptosis of human cancer cells in vitro (Seeram et al., 2006). While several studies have explored phenolic contents and phenolic compositions of berries, data on the literature varies depending on the cultivar, growth location, and season of cultivation. Therefore, a more comprehensive analysis 
of phenolic contents and compositions in different berry cultivars is still an attractive area of research. Characterizations and comparisons among different types of berries may help in deciding particular desired applications of the fruits. Recently, the consumption of berry fruits in Korea has been steadily increasing due to their potential health benefits. Among them, Korean raspberry, blueberry, aronia, mulberry, blackberry, and red raspberry, as shown in Fig. 1 are the most widely consumed berry fruits in Korea.

This study aimed at characterizing and comparing total phenol, total flavonoid, total anthocyanin and ascorbic acid contents of aronia, blueberry, Korean raspberry, blackberry, mulberry, and red raspberry fruits cultivated in South Korea as well as their antioxidant activities as determined by 2,2-diphenyl-1-picrylhydrazyl (DPPH) free radical scavenging activity, 2,2'-azino-bis(3-ethylbenzothiazoline)-6 sulphonic acid (ABTS) free radical scavenging activity, and ferric reducing antioxidant power (FRAP) assaying methods. It also attempted identification of individual phenolic compounds in the aronia cultivar using high-performance liquid chromatography/quadrupoletime of flight mass spectrometry (HPLC/Q-TOF MS).

\section{MATERIALS AND METHODS}

\section{Reagents and chemicals}

Gallic acid, quercetin, rutin, butylated hydroxyanisole, butylated hydroxytoluene, 6-hydroxy-2,5,7,8-tetramethylchromane-2-carboxylic acid (Trolox), Folin-Ciocalteu reagent, cyanidin-3-O-glucoside, ABTS diammonium salt, 2,4,6-tris(2-pyridyl)-s-triazine (TPTZ), and all other standards were purchased from Sigma-Aldrich Co. (St. Louis, MO, USA). HPLC grade methanol, acetonitrile, and deionized water were purchased from J.T. Baker Co. (Phillipsburg, NJ, USA). All the other reagents and chemicals were purchased from different commercial suppliers and were of analytical grade.

\section{Plant materials}

Aronia, blueberry, Korean raspberry, blackberry, mulberry, and red raspberry fruits cultivated in June 2017 were collected from Yongjin local market (Wanju, Korea). Each berry fruit was lyophilized, ground into fine powder using a blender and stored in $-20^{\circ} \mathrm{C}$ refrigerator until used.

\section{Extraction of phenolic compounds}

For extraction of phenolic compounds, $1.0 \mathrm{~g}$ of fruit powder was extracted with $10 \mathrm{~mL}$ of $70 \%$ methanol under sonication (Ultrasonicator, Hwashin Tech Co., Ltd., Seoul, Korea) for $30 \mathrm{~min}$ at room temperature (RT). The extraction mixture was then centrifuged at 4,500 rpm (VS-550, Vision Scientific, Daejeon, Korea) for $20 \mathrm{~min}$ and all supernatants from three extractions were combined and transferred to a new tube. The extract (berry $70 \%$ methanol extract) was then filtered through a $0.45-\mu \mathrm{m}$ membrane filter (Roshi Kaisha, Tokyo, Japan) and used for analysis.

\section{Determination of total phenol content (TPC)}

TPC of samples was determined according to the FolinCiocalteu method as described by Mauro et al. (1988) with some modifications. Briefly, $200 \mu \mathrm{L}$ of the $70 \%$

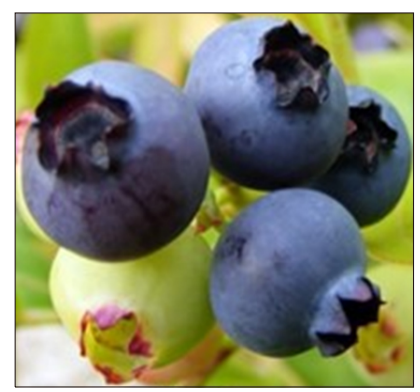

Blueberry

(Vaccinium corymbosum)

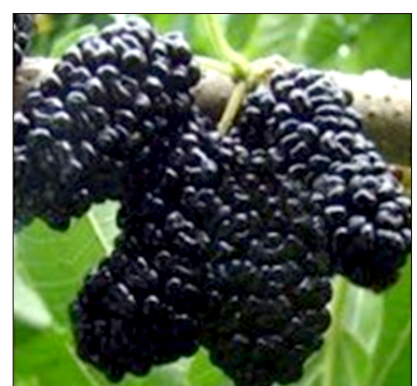

Mulberry

(Morus alba)

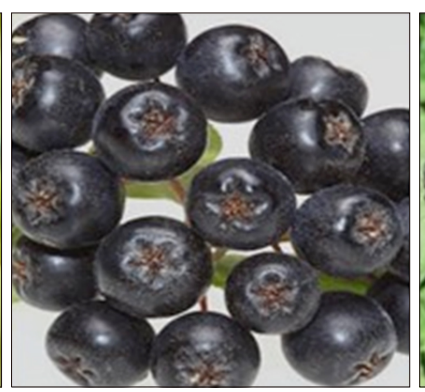

Aronia

(Aronia melanocarpa)

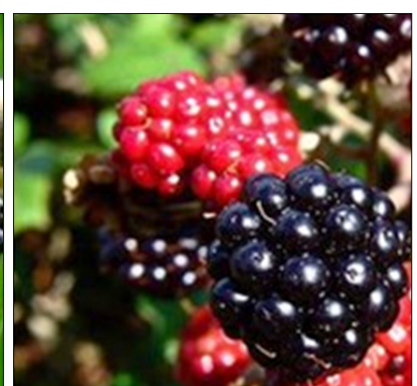

Blackberry (Rubus fruticosus)

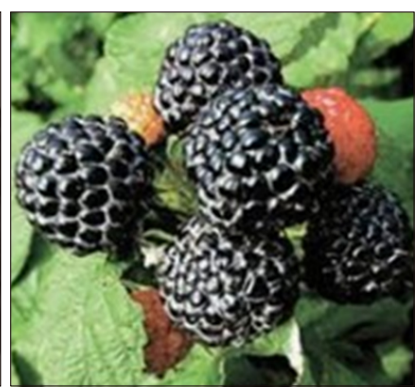

Korean raspberry

(Rubus coreanus)

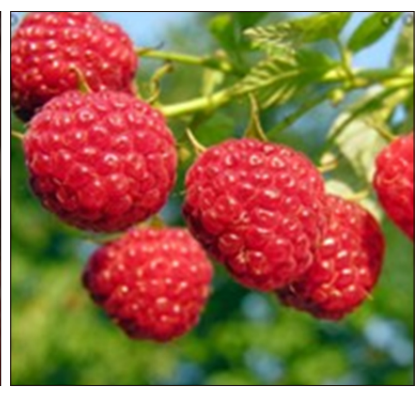

Red raspberry (Rubus crataegifolius)
Fig. 1. Photographs of Korean berry fruits used in this study. 
methanol extract was mixed with $20 \mu \mathrm{L}$ of $2 \%$ sodium carbonate, vortexed briefly, and incubated for $5 \mathrm{~min}$ at RT. Then, $20 \mu \mathrm{L}$ of $50 \%$ Folin-Ciocalteu phenol reagent was added and then the mixture was vortexed for $10 \mathrm{~s}$. After incubation for $30 \mathrm{~min}$ at RT in the dark, absorbance was read at $750 \mathrm{~nm}$ using a ultraviolet (UV)-visible spectrophotometer (Libra S22, Biochrom Ltd., Cambridge, UK) against a blank (70\% methanol). TPC was calculated based on a calibration curve of gallic acid. Results were expressed as mg gallic acid equivalent per gram lyophilized fruit [mg GAE/g dry weignt (dw)].

\section{Determination of total flavonoid content (TFC)}

TFC of samples was determined according to a method described by Zhishen et al. (1999) with slight modifications as follows. The $75 \mu \mathrm{L}$ of $5 \%$ sodium nitrite $\left(\mathrm{NaNO}_{2}\right)$ solution was added into $250 \mu \mathrm{L}$ of the $70 \%$ methanol extract of each sample and vortexed briefly. After $5 \mathrm{~min}$ incubation at RT, $10 \%$ aluminum chloride $\left(\mathrm{AlCl}_{3} \cdot 6 \mathrm{H}_{2} \mathrm{O}\right)$ was added and the mixture was vortexed. The reaction mixture was then incubated for 6 min at RT and $500 \mu \mathrm{L}$ of $1 \mathrm{~N} \mathrm{NaOH}$ was added. The total volume was adjusted to $1 \mathrm{~mL}$ with distilled water and absorbance was measured at $510 \mathrm{~nm}$ against a blank (70\% methanol). The TFC was calculated using a calibration curve of rutin and results were expressed as $\mathrm{mg}$ rutin equivalent per gram of lyophilized fruit (mg RE/g dw).

\section{Determination of total anthocyanin content (TAC)}

TAC was determined by the $\mathrm{pH}$-differential method as described by Lee et al. (2005). Two dilutions were prepared by adding $100 \mu \mathrm{L}$ of the $70 \%$ methanol extract to $1.9 \mathrm{~mL}$ of potassium chloride buffer $(\mathrm{pH} 1.0)$ and 1.9 $\mathrm{mL}$ of sodium acetate buffer ( $\mathrm{pH} 4.5)$. Each mixture was vorterxed and equilibrated for $15 \mathrm{~min}$. The absorbance of each dilution was then measured at 510 and $700 \mathrm{~nm}$ respectively. The TACs were calculated using cyanidin-3$O$-glucoside as a standard and expressed as $\mu \mathrm{g}$ or $\mathrm{mg}$ per $100 \mathrm{~g}$ dried fruit sample using the following formula.

$$
\mathrm{TAC}(\mathrm{mg} / \mathrm{L})=\mathrm{A} \times \mathrm{MW} \times \mathrm{DF} \times 1,000 / \varepsilon \times 1
$$

where A is absorbance, MW is molecular weight, DF is dilution factor, and $\varepsilon$ is the molar absorptivity, calculate pigment content as cyanidin-3-O-glucoside, where $\mathrm{MW}=$ 449.2 and $\varepsilon=26,900$, then it was converted to $\mathrm{mg}$ of $\mathrm{TAC} / 100 \mathrm{~g}$ sample.

\section{Extraction and determination of ascorbic acid}

Extraction of ascorbic acid (vitamin C) was conducted as described by Brause et al. (2003) with some modifications. Five hundred micrograms of fruit powder was dispersed in $10 \mathrm{~mL}$ of $5 \%$ meta-phosphoric acid containing $1 \%$ dithiothreitol $(\mathrm{v} / \mathrm{v})$. The extraction solution was then so- nicated for $20 \mathrm{~min}$. The extraction mixture was centrifuged at 4,500 rpm for $10 \mathrm{~min}$ and the supernatant was separated into new tubes. The supernatant was then filtered through a $0.45-\mu \mathrm{m}$ membrane filter before injection to HPLC. During analysis, the HPLC instrument was equipped with an Eclipse XDB-C18S $(4.6 \mathrm{~mm} \times 250 \mathrm{~mm}$, $5 \mu \mathrm{m}$, Agilent Technologies, Inc., Santa Clara, CA, USA) column, the flow rate was set at $0.8 \mathrm{~mL} / \mathrm{min}$, the mobile phase was water : trifluoroacetic acid $(99: 1, \mathrm{v} / \mathrm{v})$. The injection volume was $20 \mu \mathrm{L}$ and a photodiode array detector was used for the detection of ascorbic acid at $254 \mathrm{~nm}$.

\section{Analysis of phenolic acids and flavonoids by HPLC}

HPLC analysis was performed using a HPLC system (Waters, Milford, MA, USA) equipped with a 2,690 separation module and Waters 996 diode array detection (DAD) with a Sunfire-C18 column $(4.6 \mathrm{~mm} \times 250 \mathrm{~mm}$ ID, $5 \mu \mathrm{m}$, Waters). The separation was conducted in gradient mode. The mobile phase consisted of $10 \%$ acetonitrile containing $0.1 \%$ formic acid (solvent $\mathrm{A}$ ) and $90 \%$ acetonitrile containing $0.1 \%$ formic acid (solvent $B$ ). The ratio of the mobile phase was maintained at $A: B=100: 0$ (0 min), 100:0 (2 min), 90:10 (4 min), 37:63 (25 min), 50:50 (10 $\mathrm{min})$, and 100:0 (4 min), and a flow rate of $1.0 \mathrm{~mL} / \mathrm{min}$. The injection volume was $20 \mu \mathrm{L}$ and the detection wavelength was $280 \mathrm{~nm}$.

\section{Analysis of individual compounds in aronia by HPLC/Q- TOF MS}

To prepare the sample, $2.0 \mathrm{~g}$ of aronia powder was extracted twice with $15 \mathrm{~mL} \mathrm{70 \%} \mathrm{methanol} \mathrm{under} \mathrm{sonica-}$ tion for $30 \mathrm{~min}$. The extraction solution was centrifuged at 4,500 rpm for $10 \mathrm{~min}$ and the supernatants were combined $(30 \mathrm{~mL})$. For HPLC/Q-TOF MS, sample was purified using a hydrophilic-lipophilic-balanced (HLB) cartridge (225 mg, Waters) as follows. First, the HLB cartridge was conditioned by passing $5 \mathrm{~mL}$ aqueous methanol containing $3 \%$ formic acid. The $5 \mathrm{~mL}$ of the aronia methanol extract was concentrated to dryness, dissolved in $5 \mathrm{~mL}$ of $3 \%$ formic acid solution and adsorbed onto the activated HLB cartridge. The cartridge was washed with $10 \mathrm{~mL}$ of $3 \%$ formic acid solution to remove hydrophilic components and the phenolic compounds were eluted with $5 \mathrm{~mL}$ methanol. The eluate was evaporated to dryness at $40^{\circ} \mathrm{C}$ under reduced pressure, dissolved in $2 \mathrm{~mL}$ methanol, and filtrated through a $0.20 \mu \mathrm{m}$ filter immediately before HPLC/Q-TOF MS analysis.

The HPLC/Q-TOF MS analysis was performed using an Agilent 1290 HPLC system (Infinity 1260, 1290, Agilent Technologies, Inc.) equipped with a binary pump, an online degasser, an autosampler, and a thermostated column compartment coupled with a 6540 Q-TOF MS with a dual electrospray ionization (ESI) source (Agilent Technologies, Inc.). A Sunfire-C18 column (4.6 mm $\times 250$ 
$\mathrm{mm}$ ID, $5 \mu \mathrm{m}$, Waters) was used for reverse phase-HPLC separation. The separation was conducted in gradient mode. The mobile phase consisted of $10 \%$ acetonitrile containing $0.1 \%$ formic acid (solvent $\mathrm{A}$ ) and $90 \%$ acetonitrile containing $0.1 \%$ formic acid (solvent $\mathrm{B}$ ). The injection volume was $5 \mu \mathrm{L}$ at a flow rate of $0.8 \mathrm{~mL} / \mathrm{min}$ and column temperature of $35^{\circ} \mathrm{C}$. The ratio of mobile phase was maintained at $A: B=100: 0(0 \mathrm{~min}), 100: 0(5 \mathrm{~min})$, 85:15 (35 min), 77.5:22.5 (50 min), 37.5:62.5 (60 min), 0:100 (70 min), 0:100 (75 $\mathrm{min}), 100: 0$ (76 $\mathrm{min})$, and 100:0 (80 min). The Q-TOF MS detection was carried out in the negative ion ESI mode at drying gas (nitrogen) flow rate of $15 \mathrm{~L} / \mathrm{min}$, drying gas (nitrogen) temperature of $225^{\circ} \mathrm{C}$, nebulizer pressure of $310,263 \mathrm{~Pa}$, sheath gas temperature of $350^{\circ} \mathrm{C}$, capillary voltage of $3,500 \mathrm{~V}$, and collision energy of $0 \mathrm{~V}$. The mass scan range was set to $200 \sim 1,200$ mass-to-charge ratio.

\section{Antioxidant activities}

$D P P H$ radical scavenging activity: DPPH radical scavenging activity of the sample was determined according to a method described by Thaipong et al. (2006) with some modifications. The stock solution was freshly prepared by dissolving $24 \mathrm{mg}$ DPPH in methanol $(100 \mathrm{~mL})$ and the working solution was prepared by diluting stock solution with methanol to obtain an absorbance of $1.01 \pm 0.02$ units at $517 \mathrm{~nm}$ using the UV-Vis spectrophotometer. The $70 \%$ methanol extract $(20 \mu \mathrm{L})$ was added to $80 \mu \mathrm{L}$ working solution and $100 \mu \mathrm{L}$ of $0.1 \mathrm{M}$ Tris- $\mathrm{HCl}$ buffer (pH 7.4). The mixture was shaken at RT in dark conditions for $20 \mathrm{~min}$. Absorbance was measured at wavelength of $517 \mathrm{~nm}$. The calibration curve was linear between 15 and 1,500 $\mu \mathrm{M}$ Trolox. The results are expressed as $\mu \mathrm{M}$ Trolox equivalent (TE)/g dw.

ABTS free radical scavenging activity: ABTS free radical scavenging activity was determined as described by Thaipong et al. (2006) with some modifications. A mixture of ABTS (7.4 mM) solution and potassium persulfate $(2.6 \mathrm{mM})$ solution at 1:1 ratio was kept at RT for $12 \mathrm{~h}$ under dark conditions to form ABTS cation. The solution was diluted by adding methanol to obtain an absorbance of $1.10 \pm 0.02$ at $734 \mathrm{~nm}$ using a UV-Vis spectrophotometer. All the required solutions were freshly prepared for each assay. The $100 \mu \mathrm{L}$ of extract was added to $1,400 \mu \mathrm{L}$ of diluted ABTS solution and the mixture was incubated at RT for $2 \mathrm{~h}$ in the dark. After the reaction, its absorbance was measured at wavelength of $734 \mathrm{~nm}$. The calibration curve was linear between 15 and 1,500 $\mu \mathrm{M}$ Trolox. Results were expressed as $\mu \mathrm{M} \mathrm{TE} / \mathrm{g} \mathrm{dw}$.

FRAP: Ferric reducing power was determined using FRAP assay (Benzie and Strain, 1996) with some modifications. The FRAP reagent was prepared by mixing 10 volumes of $300 \mathrm{mM}$ acetate buffer ( $\mathrm{pH}$ 3.6) with 1 volume of 10 $\mathrm{mM}$ TPTZ solution in $40 \mathrm{mM} \mathrm{HCl}$ and 1 volume of 20
$\mathrm{mM}$ ferric chloride solution. The sample $(75 \mu \mathrm{L})$ was added to $1,425 \mu \mathrm{L}$ of FRAP reagent. The mixture was incubated at RT for 30 min in the dark. Then the absorbance was measured at $593 \mathrm{~nm}$. The calibration curve was linear between 15 and 1,500 $\mu \mathrm{M}$ Trolox. Results were expressed as $\mu \mathrm{M} \mathrm{TE} / \mathrm{g} \mathrm{dw}$.

Total reducing power: Total reducing power was determined as described by Oyaizu (1986) with some modifications. Reducing power reagent was prepared by mixing $5 \mathrm{~mL}$ of $200 \mathrm{mM}$ sodium phosphate buffer (pH 6.6) with $1 \%$ potassium ferricyanide $(5 \mathrm{~mL})$ in sample $(5 \mathrm{~mL})$. The mixture was incubated at $50^{\circ} \mathrm{C}$ for $20 \mathrm{~min}$ and then 5 $\mathrm{mL}$ of $10 \%$ trichloroacetic acid (w/v) were added. After filtering, sample $(5 \mathrm{~mL})$ was mixed with $5 \mathrm{~mL}$ deionized water and $1 \mathrm{~mL}$ of $0.1 \%$ ferric chloride for $10 \mathrm{~min}$, and the absorbance was measured at $700 \mathrm{~nm}$. The calibration curve was linear between 15 and 1,500 $\mu \mathrm{M}$ Trolox. Results were expressed as $\mu \mathrm{M} \mathrm{TE} / \mathrm{g} \mathrm{dw}$.

\section{Statistical analysis}

All experiments were performed in triplicate and results were expressed as mean \pm standard deviation. Statistical analyses were conducted with Graph pad prism 5 (GraphPad Software, San Diego, CA, USA) for Windows and one-way analysis of variance (ANOVA). Duncan's multiple range tests were carried out to test any significant differences among the different berry samples. Values with $P<0.05$, fixed a priori, were considered as significantly different.

\section{RESULTS AND DISCUSSION}

\section{TPC, TFC, and TAC}

The TPC and TFC of six types of berry fruits analyzed in this study are presented in Table 1 . The results show that the phenolic contents varied considerably among berry types. TPC of berries ranged from $17.0 \pm 0.7$ to $135.5 \pm 3.2$ mg GAE/g dw (Table 1). The highest TPC was observed in aronia (135.5 $\pm 3.2 \mathrm{mg} \mathrm{GAE} / \mathrm{g} \mathrm{dw}$ ) and the lowest was observed in red raspberry (17.0 $\pm 0.7 \mathrm{mg}$ GAE/g dw) among the berries investigated in this study. Fruits are suggested to be classified into three categories as low $(<100)$, medium $(100 \sim 500)$, and high (>500 mg GAE/ $100 \mathrm{~g}$ fresh weight) in phenolics based on their TPC (Vasco et al., 2008). While the TPC in this study was calculated on a dry weight basis, it can be estimated that aronia resulted as high, red raspberry as low and all the remaining berries as medium in phenolics considering the water content of berries are $80 \%$ on average.

These results are comparable with a previous study that reported a higher TPC in blackberry than raspberry (Diaconeasa et al., 2015). However, this same study reported a higher TPC in blueberry than blackberry (Dia- 
Table 1. Total phenol, total flavonoid, and total anthocyanin content of Korean berry fruits

\begin{tabular}{llccc}
\hline Common name & \multicolumn{1}{c}{ Scientific name } & $\begin{array}{c}\text { Total phenol } \\
(\mathrm{GAE} \mathrm{mg} / \mathrm{g} \mathrm{dw})\end{array}$ & $\begin{array}{c}\text { Total flavonoid } \\
\text { (RE mg/g dw) }\end{array}$ & $\begin{array}{c}\text { Total anthocyanin } \\
\text { (CYE mg/g dw) }\end{array}$ \\
\hline Blueberry & Vaccinium corymbosum & $31.2 \pm 1.2^{\mathrm{b}}$ & $4.0 \pm 0.2^{\mathrm{bc}}$ & $11.9 \pm 0.2^{\mathrm{b}}$ \\
Aronia & Aronia melanocarpa & $135.5 \pm 3.2^{\mathrm{e}}$ & $8.5 \pm 0.1^{\mathrm{d}}$ & $16.4 \pm 0.8^{\mathrm{c}}$ \\
Korean raspberry & Rubus coreanus & $66.1 \pm 3.2^{\mathrm{d}}$ & $6.0 \pm 0.1^{\mathrm{c}}$ & $24.4 \pm 0.9^{\mathrm{d}}$ \\
Mulberry & Morus alba & $69.2 \pm 2.8^{\mathrm{d}}$ & $4.8 \pm 0.3^{\mathrm{bc}}$ & $13.2 \pm 0.2^{\mathrm{b}}$ \\
Blackberry & Rubus fruticocus & $47.1 \pm 2.1^{\mathrm{c}}$ & $3.6 \pm 0.4^{\mathrm{b}}$ & $11.5 \pm 0.3^{\mathrm{b}}$ \\
Red raspberry & Rubus cartaegifolius & $17.0 \pm 0.7^{\mathrm{a}}$ & $1.0 \pm 0.0^{\mathrm{a}}$ & $2.5 \pm 0.0^{\mathrm{a}}$ \\
\hline
\end{tabular}

Values are presented as mean \pm standard deviation $(n=3)$.

Different letters (a-e) within the same column show a significant difference at the $P<0.05$ by Duncan's multiple range test. $G A E$, gallic acid equivalent; $R E$, rutin equivalent; $C Y E$, cyanidin-3-O-glucoside equivalent; dw, dry weight.

coneasa et al., 2015), which is different from the results in the present study. A study that analyzed blueberry cultivated in Korea reported a TPC of $52.6 \mathrm{mg}$ GAE/g, which is slightly higher than our result (Lee et al., 2015). It also showed a TPC of 78.3 to $8 \mathrm{mg}$ GAE/g for aronia collected from mountainous regions in Korea, which is slightly lower than our result. Such variations are suggested to be due to differences in varieties, climate and ripeness stages.

Regarding flavonoid content, a similar trend as TPC was observed. Among the different berries, the highest TFC was observed in aronia ( $8.5 \pm 0.1 \mathrm{mg} \mathrm{RE} / \mathrm{g} \mathrm{dw})$ followed by Korean raspberry $(6.0 \pm 0.1 \mathrm{mg} R E / \mathrm{g} \mathrm{dw})$, mulberry $(4.8 \pm 0.3 \mathrm{mg} R E / \mathrm{g} \mathrm{dw})$, blueberry $(4.0 \pm 0.2 \mathrm{mg}$ $\mathrm{RE} / \mathrm{g} \mathrm{dw})$, blackberry $(3.6 \pm 0.4 \mathrm{mg} \mathrm{RE} / \mathrm{g} \mathrm{dw})$, and raspberry (1.0 $\pm 0.0 \mathrm{mg} \mathrm{RE} / \mathrm{g} \mathrm{dw}$ ). A study by Chung et al. (2014) previously reported a higher TFC in aronia (32.5 $\mathrm{mg} \mathrm{RE} / \mathrm{g}$ ) than blueberries (26.3 $\mathrm{mg} \mathrm{RE} / \mathrm{g}$ ) cultivated in Korea even though the content is significantly different from our result.

TAC [cyanidin-3-O-glucoside mg (CYE)/g dw] are summarized in Table 1. The highest concentration was found in Korean raspberry $(24.4 \pm 0.9 \mathrm{mg} \mathrm{CYE} / \mathrm{g} \mathrm{dw})$ followed by aronia (16.4 $\pm 0.8 \mathrm{mg} \mathrm{CYE} / \mathrm{g} \mathrm{dw})$, mulberry $(13.2 \pm 0.2$ $\mathrm{mg} \mathrm{CYE} / \mathrm{g} \mathrm{dw})$, blueberry $(11.9 \pm 0.2 \mathrm{mg} \mathrm{CYE} / \mathrm{g} \mathrm{dw})$, and blackberry (11.5 $\pm 0.3 \mathrm{mg}$ CYE/g dw) on a dry weight basis (Table 1). The anthocyanin concentration in red raspberry was relatively much lower with only $2.55 \pm 0.09 \mathrm{mg}$ $\mathrm{CYE} / \mathrm{g} \mathrm{dw}$. These data are agreement with a previous study by Lee et al. (2015), which reported anthocyanin content on a wet basis of 3.8 and $1.6 \mathrm{mg} / \mathrm{g}$ in black raspberry and blueberry respectively (Lee et al., 2015). This study also found the lowest anthocyanin content of only $1.1 \mathrm{mg} / \mathrm{g}$ in raspberry. In a study that analyzed berry fruits from Northern Greece, anthocyanin content of blackberry and raspberry cultivars was found to range from 104 to $198 \mathrm{mg} / 100 \mathrm{~g}$ on a wet basis while those of raspberry cultivars contained much lower contents ranging from 35 to $49 \mathrm{mg} / 100 \mathrm{~g}$ on a fresh weight basis (Pantelidis et al., 2007). It shows that differences in anthocyanin contents are observed according individual colors of the fruits indicating these pigment compounds are responsible for the respective fruit colors. However, some differences seem to exist between our results and those from previous studies. Just like phenolic contents, variations are expected to occur according to varieties, climate and ripeness stages.

\section{Ascorbic acid content}

Ascorbic acid, also called vitamin C, is one of the most common water-soluble bioactive compounds found in vegetables and fruits. It exerts its antioxidant properties by reacting with oxygen present in tissues to form dehydroascorbic acid thereby inhibiting enzymes such as polyphenol oxidases (Doğan and Salman, 2007). Ascorbic acid contents of the berry samples investigated in this study are presented in Fig. 2. The results show significant differences in ascorbic acid content among the different samples. Red raspberry had the highest ascorbic acid content of [19.45 $\pm 0.67 \mathrm{mg}$ ascorbic acid equivalent (AAE)/ $\mathrm{g} \mathrm{dw}$, which is almost 5-fold higher than that of aronia (3.14 $\pm 0.12 \mathrm{mg} \mathrm{AAE} / \mathrm{g} \mathrm{dw})$. Korean raspberry, blackberry, and mulberry did not show any significant difference with ascorbic acid content of $5.64 \pm 0.23,5.62 \pm 0.44$, and $6.80 \pm 0.18 \mathrm{AAE} \mathrm{mg} / \mathrm{g} \mathrm{dw}$, respectively. Similar results have been found previously where highest ascorbic acid

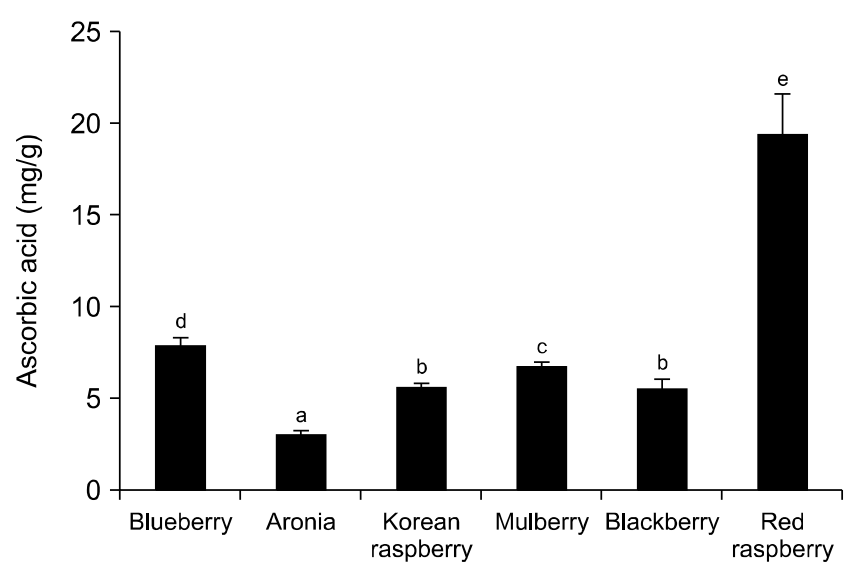

Fig. 2. Ascorbic acid content in Korean berry fruits. Values are presented as mean $\pm S D(n=3)$. Different letters (a-e) on the bars show a significant difference at the $P<0.05$ by Duncan's multiple range test. 
Table 2. Composition and amounts of phenolic acids and flavonoids detected in berry fruits

\begin{tabular}{|c|c|c|c|c|c|c|c|}
\hline \multirow[b]{2}{*}{ Compounds } & \multirow{2}{*}{$\begin{array}{c}t_{R} \\
(\mathrm{~min})\end{array}$} & \multicolumn{6}{|c|}{ Content $(\mu \mathrm{g} / \mathrm{g} \mathrm{dw})$} \\
\hline & & Blueberry & Aronia & $\begin{array}{l}\text { Korean } \\
\text { raspberry }\end{array}$ & Mulberry & Blackberry & $\begin{array}{c}\text { Red } \\
\text { raspberry }\end{array}$ \\
\hline Gallic acid & 6.4 & $401.0 \pm 10.1^{c}$ & - & $101.0 \pm 2.0^{b}$ & - & - & - \\
\hline Neochlorogenic acid & 8.6 & $926.5 \pm 23.5^{d}$ & $2,471 \cdot 5 \pm 22.3^{c}$ & $365.7 \pm 13.1^{d}$ & $669.0 \pm 11.8^{c}$ & $709.8 \pm 18.4$ & $25.0 \pm 2.7^{b}$ \\
\hline Chlorogenic acid & 9.7 & $2,188.3 \pm 29.2^{\mathrm{e}}$ & $2,473.6 \pm 44.5^{c}$ & $51.4 \pm 7.2^{\mathrm{a}}$ & $486.9 \pm 10.1^{b}$ & - & - \\
\hline$p$-Hydroxybenzoic acid & 10.8 & $27.1 \pm 1.1^{\mathrm{a}}$ & - & - & - & - & $22.9 \pm 2.0^{b}$ \\
\hline Caffeic acid & 11.4 & $17.4 \pm 2.0^{a}$ & - & - & - & - & $5.0 \pm 0.6^{a}$ \\
\hline Isovanillic acid & 11.7 & $60.8 \pm 3.7^{b}$ & - & - & - & - & - \\
\hline Rutin & 13.4 & - & $48.0 \pm 1.2^{\mathrm{a}}$ & $294.3 \pm 12.8^{d}$ & $410.5 \pm 10.6^{b}$ & - & - \\
\hline Taxifolin & 17.7 & - & $280.8 \pm 9.1^{b}$ & $180.6 \pm 10.7^{c}$ & - & - & - \\
\hline trans-Courmaric acid & 19.0 & - & - & - & $19.8 \pm 0.9^{\mathrm{a}}$ & - & - \\
\hline
\end{tabular}

Values are presented as mean \pm SD $(n=3)$.

Different letters (a-e) within the same column show a significant difference at the $P<0.05$ by Duncan's multiple range test. $t_{R}$, retention time; $d w$, dry weight; - , not detected.

contents were recorded in raspberry compared to all other types of berry samples collected in Korea as well as foreign countries such as Greece and Romania (Pantelidis et al., 2007; Diaconeasa et al., 2015; Lee et al., 2015). It is well known that ascorbic acid is one of the most important vitamins mainly obtained from fruits and vegetables in the diet.

\section{Phenolic compositions}

The composition of phenolic compounds in the methanol extracts of berries and amounts of individual compounds analyzed by HPLC are shown in Table 2 . During the HPLC analysis, 14 commercially available authentic standard phenolic compounds representing common phenolic acids and flavonoids were used, among which, only 9 compounds were detected in at least one of the berry samples (Table 2). The most common and abundant compound was neochlorogenic acid, which was detected in all samples at relatively higher amounts followed by its isomer chlorogenic acid that was also present in all samples except blackberry. These two isomers consisted of a majority of the phenolic concentration accounting for $86 \%, 93 \%, 42 \%, 72 \%$, and $82 \%$ of the total phenolic content in blueberry, aronia, Korean raspberry, mulberry, and red raspberry, respectively. In blackberry, the only compound detected was neochlorogenic at a concentration of $709.8 \pm 18.4 \mu \mathrm{g} / \mathrm{g}$. Blueberry and aronia contained a relatively much higher concentration of chlorogenic acid isomers compared to the other berries. These results are in agreement with a previous study that reported chlorogenic acid accounting for about $72 \%$ out of 13 phenolic acids and flavonoids detected and analyzed in berries (Velioglu et al., 2006). A similar study that analyzed four types of berries grown in Korea also found a much higher concentration of chlorogenic acid in blue berries where it accounted for about $94 \%$ of the 5 compounds detected (Lee et al., 2015). In this study, several phenolic acids were not able to be detected during the HPLC analysis. This is because of the fact that most phenolic acids in berries usually exist as glycosides while the commercial standards used are mainly the native forms. However, it can be observed from the results that berries are rich in chlorogenic acid, an important bioactive dietary phenolic compound that owns several therapeutic properties including antioxidant, antibacterial, cardioprotective, anti-inflammatory activities, etc. (Yun et al., 2012).

\section{Antioxidant activities}

A variety of methods have been developed to estimate the antioxidant capacities of natural products including those from berries. As the antioxidant activities of test samples can be influenced by the test methods used (Deng et al., 2012), a single antioxidant measurement method may not fairly reflect exact capacities. In this study, three of the most common antioxidant activity determination methods namely DPPH radical scavenging activity, ABTS radical scavenging activity, and FRAP assays were employed to evaluate the antioxidant activities of each berry sample.

Noticeable variations in DPPH radical scavenging activities were observed between different berry samples. The highest DPPH radical scavenging activity was observed in aronia extract $(6.2 \pm 1.2 \mu \mathrm{M} \mathrm{TE} / \mathrm{g})$ followed by Korean raspberry $(4.0 \pm 0.3 \mu \mathrm{M} \mathrm{TE} / \mathrm{g})$, blackberry $(3.1 \pm$ $0.5 \mu \mathrm{M} \mathrm{TE} / \mathrm{g})$, mulberry $(2.5 \pm 0.5 \mu \mathrm{M} \mathrm{TE} / \mathrm{g})$, and blueberry (2.4 $\pm 0.2 \mu \mathrm{M} \mathrm{TE} / \mathrm{g})$ on a dry weight basis (Fig. 3A). The value for red raspberry extract showed the lowest DPPH scavenging activity of $1.4 \pm 0.5 \mu \mathrm{M} \mathrm{TE} / \mathrm{g}$. The results in general showed positive correlations with the respective phenolic contents of each berry sample.

While all samples showed significant ABTS radical scavenging activities, aronia and Korean raspberry had the highest values with $8.9 \pm 2.2$ and $3.7 \pm 0.3 \mu \mathrm{M} \mathrm{TE} / \mathrm{g}$ on a dry weight basis respectively (Fig. 3B). Mulberry, black- 

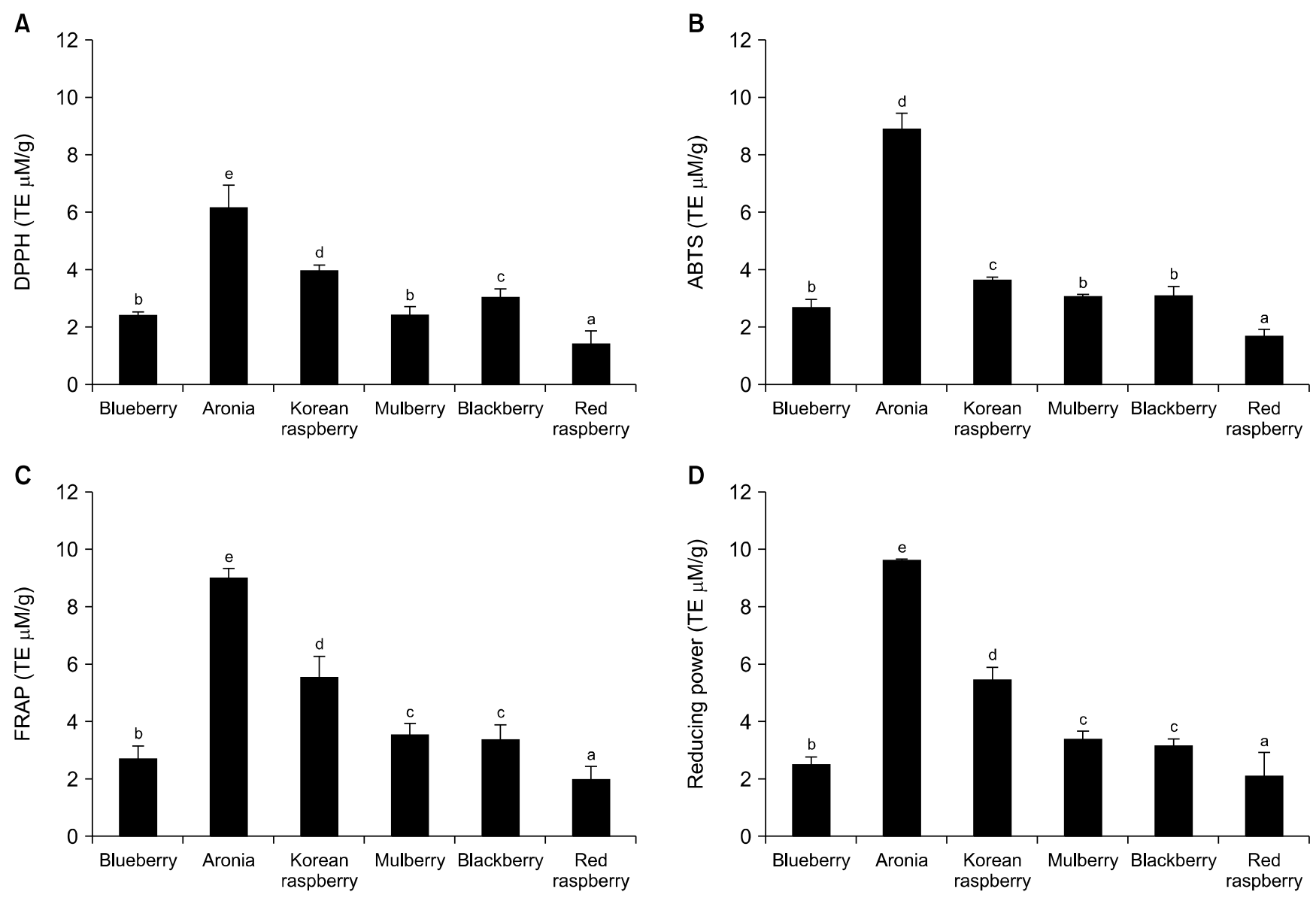

Fig. 3. Antioxidant activities of Korean berry fruits. (A) DPPH radical scavenging activity, (B) ABTS radical scavenging activity, (C) FRAP assay, and (D) reducing power. Values are presented as mean $\pm S D(n=3)$. Different letters $(a-e)$ on the bars show a significant difference at the $P<0.05$ by Duncan's multiple range test. DPPH, 2,2-diphenyl-1-picrylhydrazyl; ABTS, 2,2'-azino-bis(3-ethylbenzothiazoline)-6 sulphonic acid; FRAP, ferric reducing antioxidant power; TE, Trolox equivalent.

berry, and blueberry showed similar values of $3.1 \pm 0.1$, 3.1.0 \pm 0.9 , and $2.8 \pm 0.7 \mu \mathrm{M} \mathrm{TE} / \mathrm{g}$ on a dry weight basis respectively. The ABTS scavenging of red raspberry was also lowest $(1.7 \pm 0.6 \mu \mathrm{M} \mathrm{TE} / \mathrm{g})$ among all berry samples analyzed. ABTS scavenging capacity of all samples similarly showed strong positive correlation with the TPC.

The FRAP determination results of each berry sample are presented in Fig. 3C. It also showed significant differences among the six berry samples while still showing a positive correlation with the respective phenolic contents. Among all samples, aronia had the highest FRAP value with $9.0 \pm 0.4 \mu \mathrm{M} \mathrm{TE} / \mathrm{g}$ on a dry weight followed by Korean raspberry $(5.6 \pm 0.4 \mu \mathrm{M} \mathrm{TE} / \mathrm{g})$, mulberry $(3.4 \pm 0.5$ $\mu \mathrm{M} \mathrm{TE} / \mathrm{g})$, blackberry $(3.6 \pm 0.4 \mu \mathrm{M} \mathrm{TE} / \mathrm{g})$, and blueberry $(2.8 \pm 0.4 \mu \mathrm{M} \mathrm{TE} / \mathrm{g})$.

The reducing power determination results of each berry sample are presented in Fig. 3D. It also showed similar trends to FRAP while still showing positive correlation with the respective phenolic contents. Among all samples, aronia had the highest reducing power value with $9.6 \pm 0.05 \mu \mathrm{M} \mathrm{TE} / \mathrm{g}$ on a dry weight followed by Korean raspberry $(5.48 \pm 0.4 \mu \mathrm{M} \mathrm{TE} / \mathrm{g})$, mulberry $(3.4 \pm 0.25 \mu \mathrm{M}$ $\mathrm{TE} / \mathrm{g})$, blackberry $(3.19 \pm 0.2 \mu \mathrm{M} \mathrm{TE} / \mathrm{g})$, and blueberry

\section{$(2.25 \pm 0.26 \mu \mathrm{M} \mathrm{TE} / \mathrm{g})$.}

In summary, the antioxidant activities measure by all methods showed high correlations with the phenolic contents than vitamin $\mathrm{C}$ for each sample. Such correlations have been reported by other authors for several berry samples in different parts of the world (Pantelidis et al., 2007; Diaconeasa et al., 2015). Antioxidant capacities also somehow showed correlations with the TACs. Aronia and Korean raspberry had the highest antocyanin content compared to the others (Table 1). It can be seen from the antioxidant measurement assay results that these two particular berries have the highest value in all methods. Therefore, it can be concluded that the antioxidative properties observed in the berry fruits are attributed to their phenolic and anthocyanin contents.

\section{Identification of phenolic compounds in aronia using HPLC/Q-TOF MS}

Ultra PLC/Q-TOF MS is a new approach in the chromatographic separations and has been successfully employed for fast, high resolution separations with adequate sensitivity. This technique is capable of generating actual chemical formulas as it can measure the exact molecular 

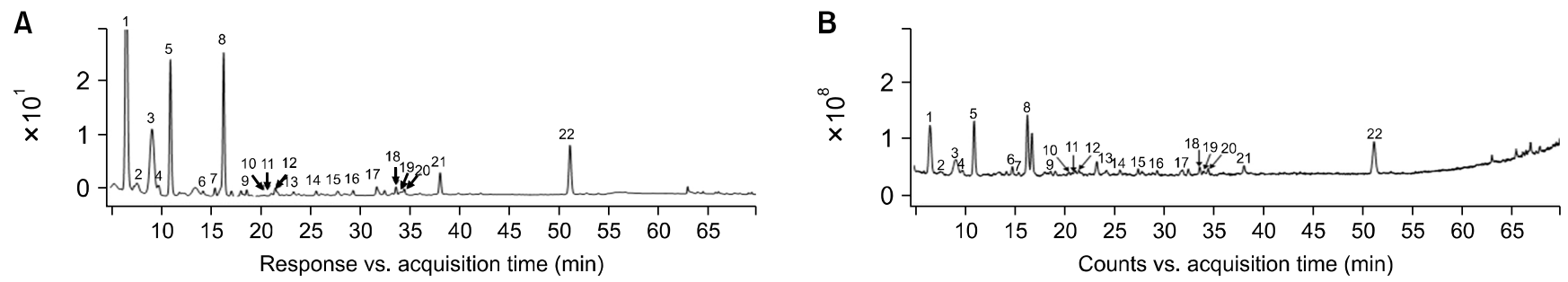

Fig. 4. HPLC/ESI-Q-TOF MS chromatograms in the negative ion mode for a $70 \%$ methanol extract of aronia fruits. (A) Ultraviolet $(280 \mathrm{~nm})$ and (B) Total ion current. HPLC/ESI-Q-TOF MS, high-performance liquid chromatography/electrospray ionization-quadrupole-time of flight mass spectrometry.

weight (monoisotopic mass) and the exact isotope distributions based on high mass accuracy and resolutions. Therefore, it has recently been widely used to identify bioactive compounds in natural products (Kim et al., 2017). In this study, the $70 \%$ methanol extract of aronia was passed through the HLB cartridge to adsorb the components and soluble substances such as sugars and amino acids were eluted with $3 \%$ formic acid. The targeted phenolic compounds were then eluted with $100 \%$ methanol and the eluate was analyzed by HPLC/Q-TOF MS. Of the 22 compounds detected in DAD $(280 \mathrm{~nm})$ and total ion current as shown in Fig. 4, 14 compounds were positively identified by comparison of HPLC retention time and mass spectral data with those of authentic standards under the same analytical conditions. The results are presented in Table 3. The identified compounds included 4 cyanidin and 1 petunidin glycosides as anthocyanin-based pigments and five quercetin glycosides with neochlorogenic acid and chlorogenic acid as hydroxycinnamic acids (Table 3). A previous study by Kim et al. (2013) reported cyanidin 3-galactoside, chlorogenic acid, cyanidin 3-arabinoside, and chlorogenic acid as major constituents in aronia. Another study also identified similar polyphenolic compounds in aronia (Oszmiański and Lachowicz, 2016). It reported that 3-galactoside, chlorogenic acid, cyanidin 3-arabinoside, and chlorogenic acid were present in higher concentrations. Among the polyphenols present in aronia, quercetin possesses many of the structural characteristics necessary for potent antioxidant activity and it is the most potent antioxidant among the aronia monomer phenolics followed by anthocyanin glycosides. A study by Denev et al. (2012) estimated that

Table 3. Phenolic compounds identified in methanol extract of aronia by HPLC/Q-TOF MS

\begin{tabular}{|c|c|c|c|c|c|c|}
\hline $\begin{array}{c}\text { Peak } \\
\text { no. }\end{array}$ & $t_{R}(\min )$ & Formula & Score & $\begin{array}{l}\text { Error } \\
\text { (ppm) }\end{array}$ & $\begin{array}{c}{[\mathrm{M}-\mathrm{H}]^{-}} \\
(\mathrm{m} / \mathrm{z})\end{array}$ & Identification $^{1)}$ \\
\hline 1 & 6.5 & $\mathrm{C}_{21} \mathrm{H}_{21} \mathrm{O}_{11}$ & 99.5 & -0.4 & 447.0932 & Cyanidin-galactoside \\
\hline 2 & 7.6 & $\mathrm{C}_{21} \mathrm{H}_{21} \mathrm{O}_{11}$ & 98.4 & -0.5 & 447.0935 & Cyanidin-glucoside \\
\hline 3 & 9.1 & $\mathrm{C}_{20} \mathrm{H}_{19} \mathrm{O}_{10}$ & 99.1 & 0.1 & 417.0826 & Cyanidin-arabinoside \\
\hline 4 & 9.7 & $\mathrm{C}_{21} \mathrm{H}_{21} \mathrm{O}_{11}$ & 99.6 & -0.7 & 447.0937 & Petunidin-arabinoside \\
\hline 5 & 10.9 & $\mathrm{C}_{16} \mathrm{H}_{18} \mathrm{O}_{9}$ & 98.8 & -0.4 & 353.0879 & Neochlorogenic acid \\
\hline 6 & 14.8 & $\mathrm{C}_{18} \mathrm{H}_{34} \mathrm{O}_{13}$ & 99.0 & -0.6 & 457.1931 & - \\
\hline 7 & 15.4 & $\mathrm{C}_{15} \mathrm{H}_{18} \mathrm{O}_{8}$ & 99.2 & -1.5 & 325.0934 & Coumaroyl-glucopyranoside \\
\hline 8 & 16.3 & $\mathrm{C}_{16} \mathrm{H}_{18} \mathrm{O}_{9}$ & 99.0 & -0.2 & 353.0878 & Chlorogenic acid \\
\hline 9 & 18.6 & $\mathrm{C}_{21} \mathrm{H}_{22} \mathrm{O}_{13}$ & 99.3 & 0.0 & 481.0988 & - \\
\hline 10 & 20.5 & $\mathrm{C}_{25} \mathrm{H}_{40} \mathrm{O}_{14}$ & 99.6 & 0.2 & 563.2345 & - \\
\hline 11 & 20.8 & $\mathrm{C}_{20} \mathrm{H}_{32} \mathrm{O}_{10}$ & 99.7 & -0.2 & 431.1924 & - \\
\hline 12 & 21.1 & $\mathrm{C}_{15} \mathrm{H}_{14} \mathrm{O}_{6}$ & 98.2 & -1.9 & 289.0724 & Epicatechin \\
\hline 13 & 24.2 & $\mathrm{C}_{20} \mathrm{H}_{30} \mathrm{O}_{12}$ & 99.0 & 0.3 & 461.1663 & - \\
\hline 14 & 25.6 & $\mathrm{C}_{27} \mathrm{H}_{30} \mathrm{O}_{17}$ & 99.3 & 0.1 & 625.1410 & Quercetin 3-sophoroside \\
\hline 15 & 27.4 & $\mathrm{C}_{26} \mathrm{H}_{44} \mathrm{O}_{16}$ & 99.8 & 0.2 & 611.2555 & - \\
\hline 16 & 29.3 & $\mathrm{C}_{26} \mathrm{H}_{28} \mathrm{O}_{16}$ & 99.5 & 0.0 & 595.1304 & Quercetin 3-sambubioside \\
\hline 17 & 32.5 & $\mathrm{C}_{27} \mathrm{H}_{30} \mathrm{O}_{16}$ & 99.8 & 0.1 & 609.1460 & Rutin \\
\hline 18 & 33.6 & $\mathrm{C}_{21} \mathrm{H}_{20} \mathrm{O}_{12}$ & 99.0 & 0.0 & 463.0881 & Quercetin galactoside \\
\hline 19 & 34.0 & $\mathrm{C}_{20} \mathrm{H}_{26} \mathrm{O}_{9}$ & 98.8 & -0.6 & 409.1507 & - \\
\hline 20 & 34.4 & $\mathrm{C}_{21} \mathrm{H}_{20} \mathrm{O}_{12}$ & 99.5 & -0.2 & 463.0883 & Quercetin $3-\beta-D$-glucoside \\
\hline 21 & 38.0 & $\mathrm{C}_{21} \mathrm{H}_{20} \mathrm{O}_{12}$ & 99.2 & 0.2 & 463.0881 & Quercetin glucoside (iso) \\
\hline 22 & 51.1 & $\mathrm{C}_{15} \mathrm{H}_{10} \mathrm{O}_{4}$ & 98.8 & -1.7 & 253.0510 & - \\
\hline
\end{tabular}

HPLC/Q-TOF MS, high-performance liquid chromatography/quadrupole-time of flight mass spectrometry; m/z, mass-to-charge ratio; - , unknown.

${ }^{10}$ Compounds were identified by comparison of HPLC retention times and Q-TOF MS data with those of authentic standards. 
anthocyanins, flavonols, and hydroxycinnamic acids contribute about $59.4 \%$ of the total antioxidant activity of chokeberry without assuming the possible synergism/antagonism between the individual antioxidants. Therefore, the strong antioxidant activity observed for Korean aronia in this study is suggested to be attributed to the presence of quercetin derivatives and hydroxycinnamic acids.

In conclusions, the phenolic compositions and antioxidant activities of six different types of berry fruits (aronia, blueberry, Korean raspberry, blackberry, mulberry, and red raspberry) were analyzed. In addition, identification and quantification of individual phenolic compounds was carried out using HPLC and HPLC/Q-TOF MS. Aronia showed the highest TPC and TFC values among all investigated berry samples. With regard to anthocyanin content Korean raspberry contained the highest amount followed by aronia. While red raspberry displayed the lowest phenolic and anthocyanin contents, its ascorbic acid content was found to be more than 2-fold higher compared to the other berries. The antioxidant activity values highly correlated with the phenolic and anthocyanin contents indicating the antioxidant activity of berry samples is due to the these compounds. The antioxidant compounds found in aronia mainly include cyanidin and quercetin derivatives.

\section{AUTHOR DISCLOSURE STATEMENT}

The authors declare no conflict of interest.

\section{REFERENCES}

Benzie IF, Strain JJ. The ferric reducing ability of plasma (FRAP) as a measure of "antioxidant power": the FRAP assay. Anal Biochem. 1996. 239:70-76.

Brause AR, Woollard DC, Indyk HE. Determination of total vitamin $C$ in fruit juices and related products by liquid chromatography: interlaboratory study. J AOAC Int. 2003. 86:367-374.

Chung HJ. Comparison of total polyphenols, total flavonoids, and biological activities of black chokeberry and blueberry cultivated in Korea. J Korean Soc Food Sci Nutr. 2014. 43:1349-1356.

Denev PN, Kratchanov CG, Ciz M, Lojek A, Kratchanova MG. Bioavailability and antioxidant activity of black chokeberry (Aronia melanocarpa) polyphenols: in vitro and in vivo evidences and possible mechanisms of action: a review. Compr Rev Food Sci Food Saf. 2012. 11:471-489.

Deng GF, Xu XR, Guo YJ, Xia EQ, Li S, Wu S, et al. Determination of antioxidant property and their lipophilic and hydrophilic phenolic contents in cereal grains. J Funct Foods. 2012. 4:906914.

Diaconeasa Z, Ranga F, Rugină D, Leopold L, Pop O, Vodnar D, et al. Phenolic content and their antioxidant activity in various berries cultivated in Romania. Food Sci Technol. 2015. 72:99103.

Doğan S, Salman Ü. Partial characterization of lettuce (Lactuca sativa L.) polyphenol oxidase. Eur Food Res Technol. 2007. 226: 93-103.
Giovanelli G, Buratti S. Comparison of polyphenolic composition and antioxidant activity of wild Italian blueberries and some cultivated varieties. Food Chem. 2009. 112:903-908.

Grosso G, Stepaniak U, Micek A, Stefler D, Bobak M, Pająk A. Dietary polyphenols are inversely associated with metabolic syndrome in Polish adults of the HAPIEE study. Eur J Nutr. 2017. 56:1409-1420.

Kalt W, Ryan DA, Duy JC, Prior RL, Ehlenfeldt MK, Vander Kloet SP. Interspecific variation in anthocyanins, phenolics, and antioxidant capacity among genotypes of highbush and lowbush blueberries (Vaccinium section cyanococcus spp.). J Agric Food Chem. 2001. 49:4761-4767.

Kim B, Ku CS, Pham TX, Park Y, Martin DA, Xie L, et al. Aronia melanocarpa (chokeberry) polyphenol-rich extract improves antioxidant function and reduces total plasma cholesterol in apolipoprotein E knockout mice. Nutr Res. 2013. 33:406-413.

Kim YJ, Kim HW, Lee MK, Jang HH, Hwang YJ, Choe JS, et al. Comparison of flavonoid characteristics between blueberry (Vaccinium corymbosum) and black raspberry (Rubus coreanus) cultivated in Korea using UPLC-DAD-QTOF/MS. Korean J Environ Agric. 2017. 36:87-96.

Lee J, Durst RW, Wrolstad RE. Determination of total monomeric anthocyanin pigment content of fruit juices, beverages, natural colorants, and wines by the $\mathrm{pH}$ differential method: collaborative study. J AOAC Int. 2005. 88:1269-1278.

Lee Y, Lee JH, Kim SD, Chang MS, Jo IS, Kim SJ, et al. Chemical composition, functional constituents, and antioxidant activities of berry fruits produced in Korea. J Korean Soc Food Sci Nutr. 2015. 44:1295-1303.

Liu YJ, Zhan J, Liu XL, Wang Y, Ji J, He QQ. Dietary flavonoids intake and risk of type 2 diabetes: a meta-analysis of prospective cohort studies. Clin Nutr. 2014. 33:59-63.

Mauro MC, Vaillant V, Tey-Rulh P, Mathieu Y, Fallot J. In vitro study of the relationship between Vitis vinifera and Eutypa lata (Pers.: Fr.) Tul. I. Demonstration of toxic compounds secreted by the fungus. Am J Enol Vitic. 1988. 39:200-204.

Murphy MM, Barraj LM, Herman D, Bi X, Cheatham R, Randolph RK. Phytonutrient intake by adults in the United States in relation to fruit and vegetable consumption. J Acad Nutr Diet. 2012. 112:222-229.

Oyaizu M. Studies on products of browning reaction: antioxidative activities of products of browning reaction prepared from glucosamine. Jpn J Nutr Diet. 1986. 44:307-315.

Oszmiański J, Lachowicz S. Effect of the production of dried fruits and juice from chokeberry (Aronia melanocarpa L.) on the content and antioxidative activity of bioactive compounds. Molecules. 2016. 21:1098. https://doi.org/10.3390/molecules21081098

Pantelidis GE, Vasilakakis M, Manganaris GA, Diamantidis G. Antioxidant capacity, phenol, anthocyanin and ascorbic acid contents in raspberries, blackberries, red currants, gooseberries and Cornelian cherries. Food Chem. 2007. 102:777-783.

Randhir R, Lin YT, Shetty K. Stimulation of phenolics, antioxidant and antimicrobial activities in dark germinated mung bean sprouts in response to peptide and phytochemical elicitors. Process Biochem. 2004. 39:637-646.

Sariburun E, Sahin S, Demir C, Türkben C, Uylaşer V. Phenolic content and antioxidant activity of raspberry and blackberry cultivars. J Food Sci. 2010. 75:C328-C335.

Seeram NP, Adams LS, Zhang Y, Lee R, Sand D, Scheuller HS, et al. Blackberry, black raspberry, blueberry, cranberry, red raspberry, and strawberry extracts inhibit growth and stimulate apoptosis of human cancer cells in vitro. J Agric Food Chem. 2006. 54:9329-9339.

Thaipong K, Boonprakob U, Crosby K, Luis CZ, Byrne DH. Comparison of ABTS, DPPH, FRAP, and ORAC assays for estimating antioxidant activity from guava fruit extracts. J Food Compos Anal. 2006. 19:669-675. 
Türkben C, Sarıburun E, Demir C, Uylaşer V. Effect of freezing and frozen storage on phenolic compounds of raspberry and blackberry cultivars. Food Anal Methods. 2010. 3:144-153.

Vasco C, Ruales J, Kamal-Eldin A. Total phenolic compounds and antioxidant capacities of major fruits from Ecuador. Food Chem. 2008. 111:816-823.

Velioglu YS, Ekici L, Poyrazoglu ES. Phenolic composition of European cranberrybush (Viburnum opulus L.) berries and astringency removal of its commercial juice. Int J Food Sci Technol. 2006. 41:1011-1015.

Velderrain-Rodríguez GR, Palafox-Carlos H, Wall-Medrano A,
Ayala-Zavala JF, Chen CY, Robles-Sánchez M, et al. Phenolic compounds: their journey after intake. Food Funct. 2014. 5:189-197.

Yun N, Kang JW, Lee SM. Protective effects of chlorogenic acid against ischemia/reperfusion injury in rat liver: molecular evidence of its antioxidant and anti-inflammatory properties. J Nutr Biochem. 2012. 23:1249-1255.

Zhishen J, Mengcheng T, Jianming W. The determination of flavonoid contents in mulberry and their scavenging effects on superoxide radicals. Food Chem. 1999. 64:555-559. 